\title{
Response of hydrological processes to climate change in the middle reaches of the Yellow River, China
}

\author{
XIAOLEI YAO ${ }^{1}$, XINGQI CUI ${ }^{1}$, JINGSHAN YU ${ }^{\mathbf{1}} \&$ WENCHAO SUN ${ }^{\mathbf{1}, \mathbf{2}}$ \\ 1 College of Water Sciences, Beijing Normal University, Xinjiekouwai Street 19, 100875 Beijing, China. \\ 2 Joint Center for Global Change Studies, Beijing 100875, China \\ jingshan@bnu.edu.cn
}

\begin{abstract}
According to the IPCC Fourth Assessment, the temperature and evapotranspiration will increase in the future. As a sensitive region to climate change, hydrological process in the middle reaches of the Yellow River will be significantly affected by climate change. In this study, water resources change in the future for a typical basin there: Lushi basin is assessed using the Soil and Water Assessment Tool (SWAT) hydrological model. Downscaled ensemble output from sixteen General Circulation Models (GCMs) for the A1B emission scenario in the 2050s was input to SWAT as the regional climate change scenario. The prediction shows that ET of this basin increases in winter and spring, and decreases in summer and autumn, and the streamflow increases throughout the year. The increased streamflow will probably improve the water demand guarantee and be conducive to crop growth in winter and spring, and may improve the flood risk in summer.
\end{abstract}

Key words climate change; water resource; SWAT; the Yellow River

\section{INTRODUCTION}

Climate change has affected the social economic policymaking, and has focused more and more attention to environmental protection (Crossman et al., 2013). Xu et al. (2005) and Jiang et al. (2007) argued that the impact of climate change on water resources and corresponding countermeasures against climate change have been the focus of scientific investigation over the past two decades. Due to the socio-economic importance of water resources, future hydrological processes need to be assessed as soon as possible. In some previous studies, the future climate scenario is extrapolated from the historical data and their trends (Araujo and New, 2007), which ignores the uncertainty in climate change and the prediction error (Shi et al., 2013). In order to reduce the uncertainty, modelling has become an effective tool to predict future climate (Christensen and Christensen, 2007). Future climate scenarios predicted by General Circulation Models (GCMs) have been adopted as the available tool for obtaining the future climate information (Bates et al., 2008; Whitehead et al., 2009), and have been widely applied in much research (Mo et al., 2013; Zhang et al., 2011). The arid and semi-arid region is sensitive to climate change (Liu et al., 2011). Hydrological processes, the soil water content and vegetation evapotranspiration in arid and semi-arid regions will be obviously affected by future climate change (Brown and Rosenberg, 1994).

The middle reaches of the Yellow River is an arid and semi-arid region with high intensity of human activities, where water resources play an important role in regional development. Therefore, the influence of future climate change on hydrological process research in this region must be explored intensively. The purpose of this study is to evaluate the impact of climate change on hydrology and water resources in Lushi basin, a typical basin in the middle reaches of the Yellow River. The rainfall-runoff processes will be simulated using a semi-distributed hydrological model: Soil and Water Assessment Tool (SWAT). Ensemble prediction of downscaled output from sixteen GCMs for the A1B emissions scenario in 2050s will be used to make the future climate scenario, which will be utilized as forcing data in SWAT to predict the changes of water cycle due to climate change.

\section{STUDY AREA AND METHODOLOGY}

\section{Study area}

Lushi River is the upstream of a tributary in the middle reaches of the Yellow River in China (Fig. 1), which has a total land area of $3902 \mathrm{~km}^{2}$. According to a $90-\mathrm{m}$ elevation map, the basin 
elevation ranges between 600 and $2300 \mathrm{~m}$ and falls from the northwest to the southeast. The north is a mountainous area, whose area is about $33 \%$ of this basin. The central and western parts of the basin is hilly area, covering the loess terrace and hills, whose area account for $59 \%$ of the basin. The eastern downstream part is valley plains, with terraces and flood plains. The main landuse/land cover types are forest, grassland and farmland. The main soil types are brown native soil and brown loam. According to statistical analysis of data of 20 precipitation stations for many years in this basin, the average annual precipitation is $642 \mathrm{~mm}$, of which approximately $60 \%$ happens in the wet season from June to September.

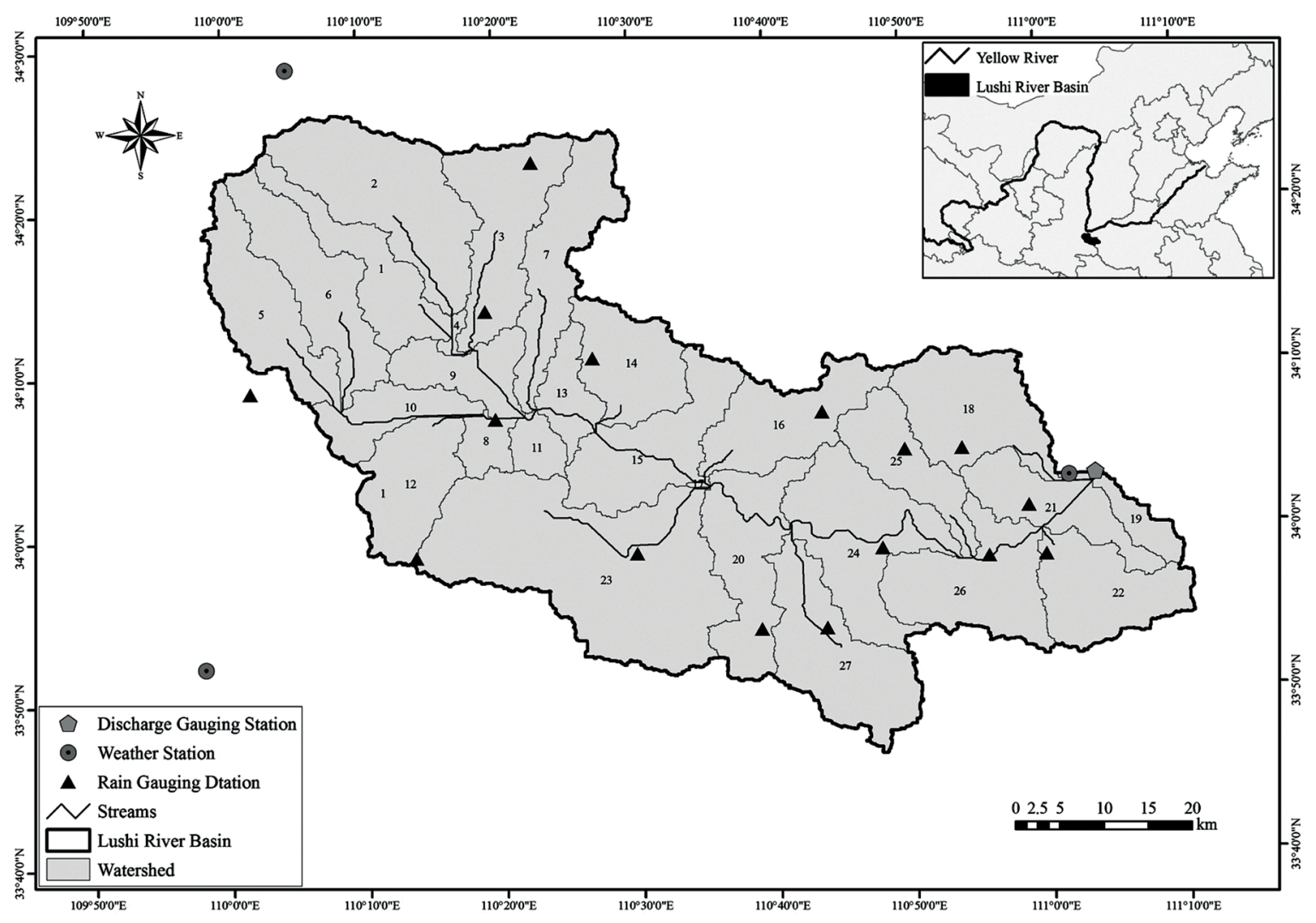

Fig. 1 Lushi Basin and sub-basin distribution.

\section{SWAT model}

It is difficult to analyse the hydrological processes in large basins such as the study basin, without a hydrological model. Hydrological models are a useful tool in management planning. From a theoretical viewpoint, a physical model represents the underlying hydrological and land surface processes in greater detail than conceptual or statistical models (Beven, 2001). The SWAT model is a conceptual physically-based model developed by the United States Department of Agriculture (USDA) for evaluating watershed hydrology and water quality that operates on a daily time step (Neitsch, 2011). In this model, the simulated watershed can be divided into explicit parameterized smaller sub-basins and distinct hydrological response units (HRUs). The HRUs are delineated by overlaying topography, soil maps and land-use maps, and are assumed to be homogeneous with respect to their hydrological properties. The modelling process of SWAT can simultaneously consider hydrological, environmental and biological processes as well as land management based on available data (Jayakrishnan, 2005; Wu, 2007; Douglas-Mankin, 2010; Lam, 2010).

The Nash-Sutcliffe $\left(E_{N S}\right)$ coefficient of efficiency (Nash and Sutcliffe, 1970) and deterministic coefficient $\left(R^{2}\right)$ are used as the objective function for optimizing the model performance. They are defined as: 


$$
\begin{aligned}
& E_{N S}=1-\frac{\sum_{i=1}^{n}\left(Q_{m, i}-Q_{s, i}\right)^{2}}{\sum_{i=1}^{n}\left(Q_{m, i}-\overline{Q_{m}}\right)^{2}} \\
& R^{2}=\frac{\left[\sum_{i=1}^{n}\left(Q_{m, i}-\overline{Q_{m}}\right)\left(Q_{S, i}-\overline{Q_{S}}\right)\right]^{2}}{\sum_{i=1}^{n}\left(Q_{m, i}-\overline{Q_{m}}\right)^{2} \sum_{i=1}^{n}\left(Q_{S, i}-\overline{Q_{S}}\right)^{2}}
\end{aligned}
$$

where $Q_{m}\left(\mathrm{~m}^{3} \mathrm{~s}^{-1}\right)$ and $Q_{s}\left(\mathrm{~m}^{3} \mathrm{~s}^{-1}\right)$ are the observed and simulated streamflow at time step $i, \overline{Q_{m}}$ $\left(\mathrm{m}^{3} \mathrm{~s}^{-1}\right)$ is the average observed streamflow, and $\overline{Q_{\mathrm{s}}}\left(\mathrm{m}^{3} \mathrm{~s}^{-1}\right)$ is the average simulated streamflow for the whole period.

\section{Data preparation}

A digital elevation map (DEM) was used for extracting the flow direction needed for the hydrological modelling. The land-use map was derived by the Chinese Academy of Sciences, and shows the dominant land-use types. Approximately $52 \%$ of the total area was covered by forest, whereas grassland covered $26 \%$, and the remaining $22 \%$ was farmland. Regional land-use/land cover classification and definitions was showed in Table 1. The soil map in the basin was compiled from the Chinese national 1:1000 000 scale soil map. The physical properties of these soils were taken from the China Soil Scientific Database (http://www.soil.csdb.cn/). The DEM, land use, soil and observed rainfall of 20 local rainfall stations and meteorological data of three national weather stations were the input to SWAT. Observed discharge (from 1990-1997) at the basin outlet was used to calibrate the parameters.

Table 1 The land use/land cover classification and definition.

\begin{tabular}{lll}
\hline & Abbreviation & Definition \\
\hline 1 & RICE & paddy land, natural vegetation mosaic \\
2 & AGRL & farmlands \\
3 & FRST & forest-mixed \\
4 & MESQ & shrub wood \\
5 & ORCD & orchard \\
6 & PAST & grasslands \\
7 & WATR & stream, river \\
8 & URBN & urban build-up, rural settlements \\
\hline
\end{tabular}

\section{FUTURE SCENARIOS OF CLIMATE CHANGE}

In this study, the future regional precipitation and temperature projected by the ensemble of 16 GCMs under the A1B emissions scenario were derived from the Climate Wizard dataset (available at: http://www.climatewizard.org/index.html) for the 2050s (2040-2069). The seasonal precipitation relative change and mean temperature absolute change were downscaled to the resolution of $50 \mathrm{~km}$ using an empirical statistical method ( $\mathrm{Fu}$ et al., 2007). Both the daily temperature and precipitation data for scenario were the input to SWAT to simulate the future hydrological regime in the 2050s. The simulation for the period of 1990-1997 is considered as the baseline period. The difference of hydrological process between these two period's simulations is considered as the impact of climate change.

Figure 2 shows averaged relative change of seasonal mean precipitation and absolute change of mean temperature between reference period and future climate scenario in 2050 s respectively. The precipitation increases all the year. For winter, significant increase of precipitation is observed 
(30\%). For summer and autumn, the increased proportion of rainfall is less. For absolute change of seasonal mean temperature, it increases all the year with an average change of 3.5 degree Centigrade. The winter warming will probably improve the availability of the heat resource and prolong the season of crop growing. Meanwhile, rising temperature will also probably increase evapotranspiration and decrease the water resource on the Earth's surface.
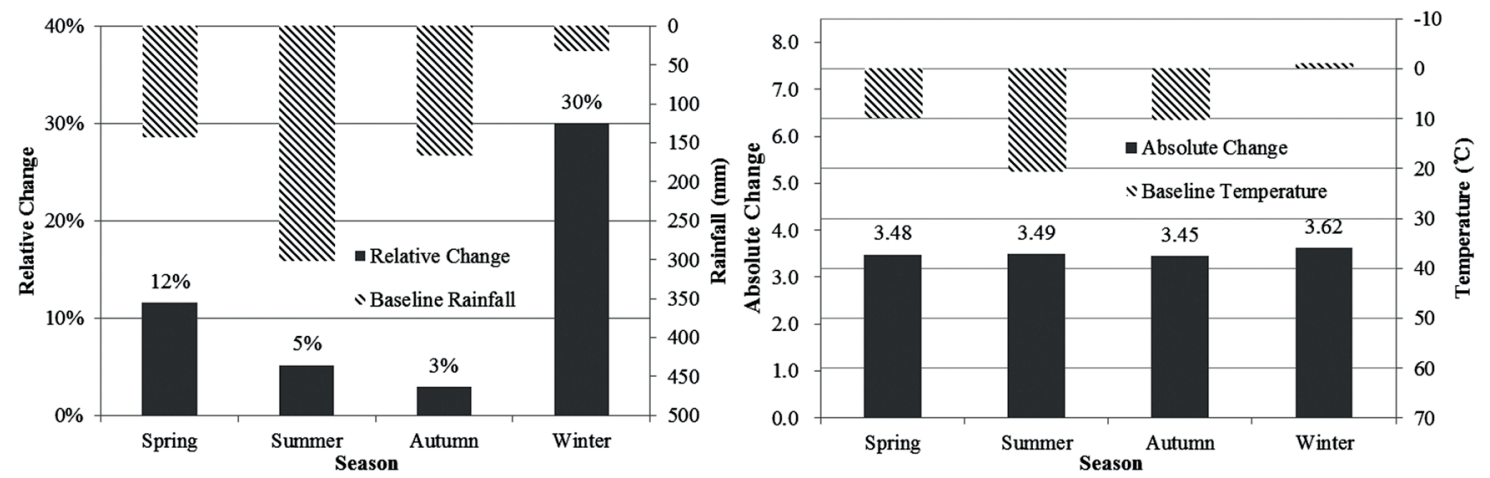

Fig. 2 Basin averaged changes of seasonal mean precipitation and temperature between baseline and future climate scenario in $2050 \mathrm{~s}$.

\section{RESULTS AND DISCUSSION}

The calibration and validation periods for streamflow are 1990-1995 and 1996-1997, respectively. Figure 3 shows the observed and simulated monthly streamflow in calibration and validation. The model performance for calibration and validation period for a monthly time-step is tabulated in Table 2 . The performance, especially the result of $E_{N S}$, is not very satisfactory because a large amount of moisture returned to the atmosphere in the form of evapotranspiration (ET) in this basin. And the observed ET data for the whole basin are not available. The performance of discharge indicates that the simulation of streamflow by SWAT model is reasonable for this basin. The reasonable performance justifies the application of SWAT for the impact assessment planned.

The daily meteorological data of 2050s A1B scenario was used as input to SWAT for simulating hydrological processes in the future. The seasonal relative changes of ET and streamflow between the baseline period and the 2050s scenario are depicted in Fig. 4. The ET increases in the 2050s in winter and spring. As mean temperatures in whole year are higher in
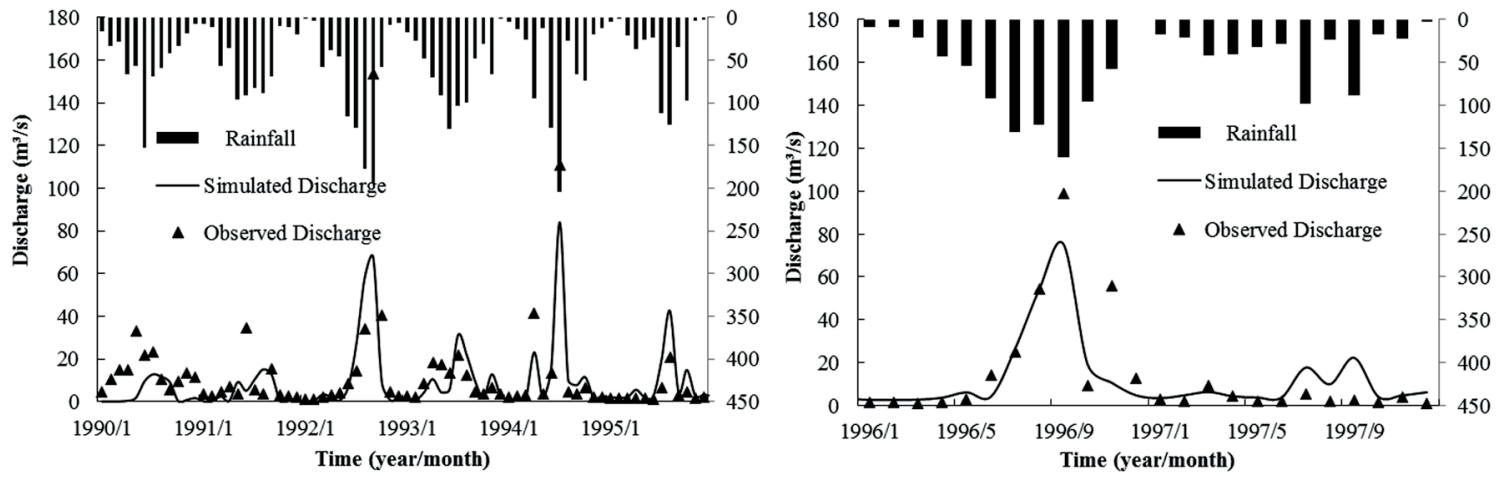

Fig. 3 Results of calibration and validation.

Table 2 Model performance for calibration and validation.

\begin{tabular}{llll}
\hline & Simulation Period & $R^{2}$ & $E_{N S}$ \\
\hline Calibration & $1990-1995$ & 0.65 & 0.56 \\
Validation & $1996-1997$ & 0.74 & 0.59 \\
\hline
\end{tabular}


the 2050s, more energy is available for water to evaporate or transpire. The increased rainfall and temperature make it the most probable reason of ET increasing in winter and spring. Meanwhile, the reduction of ET in summer and autumn is considered as a comprehensive outcome of many factors. These are mainly solar radiation, temperature, relative humidity and wind speed. With the increased rainfall in summer and autumn, the solar radiation may decrease and the relative humidity may increase, which will lead to the decreased EI (Cohen et al., 2002; Qiu and Liu, 2003).

The streamflow in 2050s exhibits an increasing trend over the whole year, with degrees varying from $17 \%$ (spring) to $25 \%$ (autumn). This can be explained as a consequence of increasing rainfall and decreased ET in summer and autumn. And the effect of increased rainfall in winter and spring is larger than the effect of increased ET. In summer, the improved streamflow will enhance the flooding risk. In winter and spring, the increased streamflow will improve the guarantee of water demand and be conducive to the growth of crops.

From the viewpoint of water resource availability, the contradiction between supply and demand of water resources will be alleviated in the future. Especially in the spring and winter, the agricultural water will be guaranteed. ET and streamflow temporal change will probably lead to the variation of land use/cover.
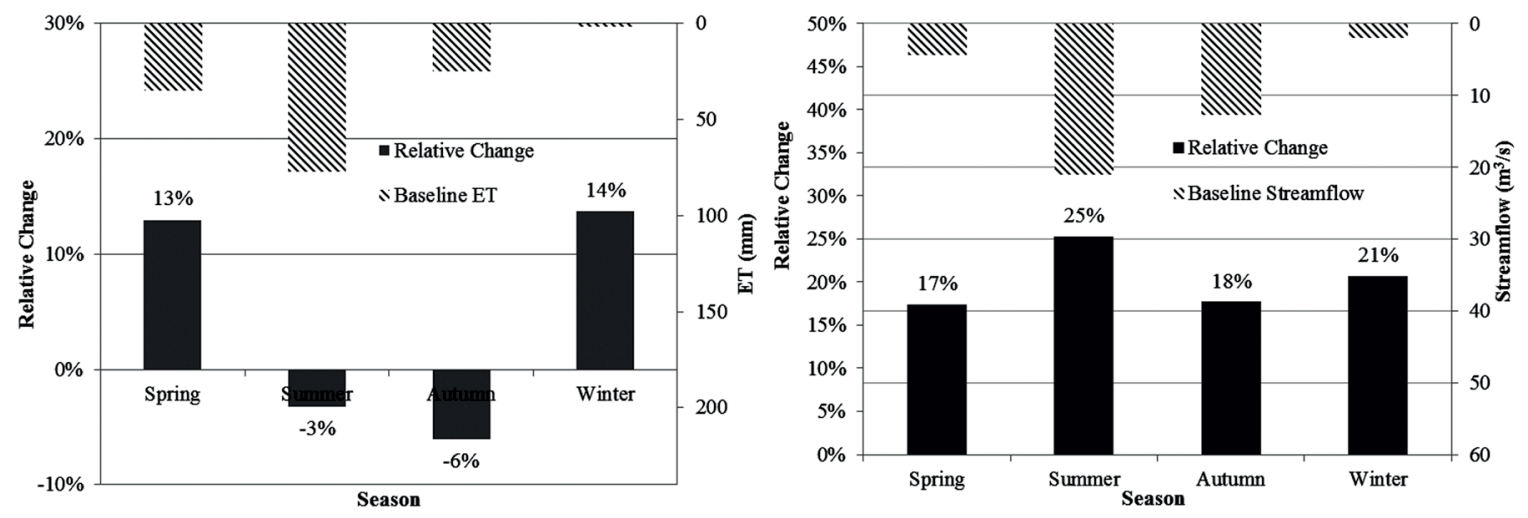

Fig. 4 Basin averaged changes of seasonal mean ET and streamflow between baseline and future climate scenario in 2050 s.

\section{CONCLUSION}

Research about water resources availability change in future scenarios plays a major role in future agricultural production as well as in local social and economic development. To evaluate the influences of climate change on water resources in Lushi basin, GCMs and SWAT hydrological model were applied to predict the hydrological processes in this basin. By comparing the simulation data with baseline streamflow data, it was indicated that this method can make fairly reasonable hydrological predictions. After constructing a regional climate change scenario in this basin, the projected meteorological variables were input to the SWAT model for predicting hydrological processes in the 2050s.

This prediction shows that ET in this basin will increase in winter and spring and decrease in summer and autumn; the water resources will increase all through the year, which will lead to the seasonal migration of hydrological processes. In winter and spring, the increased streamflow will improve the guarantee of water supply and be conducive to the growth of crops. While in summer, the enhanced flood damage will bring serious soil erosion and cause huge social and economic losses. Therefore, the study of flood forecasting and warning and resource utilization should be paid more attention, and water supply and drainage facilities in cities should be strengthened. This result may benefit the making of reasonable water resource management policy in Lushi basin. To make the policy and decisions more targeted, an analysis of the water demand is necessary. 
Acknowledgements This study was supported by the National Key Technology R\&D Program (Grant No.: 2013BAB05B04), the National Natural Science Foundation of China (Grant No.: 41201018), the Fundamental Research Funds for the Central Universities and the Strategic Environmental Assessment Project of Central China Region organized by the Ministry of Environmental Projection of China.

\section{REFERENCES}

Araujo, M.B. and New, M. (2007) Ensemble forecasting of species distributions. Trends in Ecology \& Evolution 22(1), 42-47. Bates, B., et al. (2008). Climate change and water. Intergovernmental Panel on Climate Change (IPCC).

Beven, K.J. (2001) Rainfall-Runoff Modelling: The Primer., Wiley, Chichester.

Brown, R. and Rosenberg, N., (1994). Sensitivity of crop yield and water use to change in a range of climatic factors and $\mathrm{CO}_{2}$ concentrations: a simulation study applying EPIC to the central USA. Agricultural and Forest Meteorology 83, 171-203.

Christensen, J.H. and Christensen, O.B., (2007). A summary of the PRUDENCE model projections of changes in European climate by the end of this century. Climatic Change 81(1), 7-30.

Cohen, S., Ianetz, A. and Stanhill, G., (2002). Evaporative climate changes at Bet Dagan, Israel, 1964-1998. Agricultural and Forest Meteorology 111(2), 83-91.

Crossman, J. et al., (2013). Impacts of climate change on hydrology and water quality: Future proofing management strategies in the Lake Simcoe watershed, Canada. Journal of Great Lakes Research 39(1), 19-32.

Douglas-Mankin, K.R.S.R., (2010). Soil and Water AssessmentTool (SWAT) model: current developments and applications. Transactions of the ASABE 53, 1423-1431.

Fu, G., Charles, S.P. and Chiew, F.H., (2007). A two-parameter climate elasticity of streamflow index to assess climate change effects on annual streamflow. Water Resources Research 43(11). W11419, doi:10.1029/2007WR005890

Jayakrishnan, R.S.R.S. (2005). Advances in the application of the SWAT model for water resources management. Hydrological Processes 19(3), 749-762.

Jiang, T. et al. (2007). Comparison of hydrological impacts of climate change simulated by six hydrological models in the Dongjiang Basin, South China. Journal of Hydrology 336(3-4), 316-333.

Lam, Q.D.S.B., (2010). Modelling point and diffuse source pollutionof nitrate in a rural lowland catchment using the SWAT model. Agricultural Water Management 2(97), 317-325.

Liu, J., et al. (2011). Response of Water Resources in the Yellow River Basin to Global Climate Change. Journal of Arid Land, 28(5), 860-865 (in Chinese)

Mo, X., et al. (2013). Impacts of climate change on crop evapotranspiration with ensemble GCM projections in the North China Plain. Climatic Change 120(1-2), 299-312.

Nash, J. and Sutcliffe, J., (1970). River flow forecasting through conceptual models: Part I -A discussion of principles. Journal of Hydrology 10(3), 282-290.

Neitsch, S.L., et al. (2011). Soil and Water Assessment Tool theoretical documentation: Version 2009. Texas Water Resources Institute Technical Report 406. Texas A\&M Univ. System, College Station.

Qiu, X. and Liu, C., (2003). Changes of pan evaporation in the recent 40 years over the Yellow River Basin. Journal of Natural Resources 18(4), 437-442 (in Chinese)

Shi, Q., et al. (2013) Impacts of cultivated land reclamation on the climate and grain production in Northeast China in the Future 30 Years. Advances in Meteorology 8, doi:10.1155/2013/853098

Whitehead, P., et al. (2009). A review of the potential impacts of climate change on surface water quality. Hydrological Sciences Journal 1(54), 1-6.

Wu, K.S.J.C., (2007). Hydrologic response to climatic variability in a Great Lakes Watershed: a case study with the SWAT model. Journal of Hydrology 337, 187-199.

Xu, C., Widén, E. and Halldin, S., (2005). Modelling hydrological consequences of climate change-progress and challenges. Advances in Atmospheric Sciences 22(6), 789-797.

Zhang, X.C., et al. (2011). Trend and uncertainty analysis of simulated climate change impacts with multiple GCMs and emission scenarios. Agricultural and Forest Meteorology 151(10), 1297-1304. 